\title{
Subclinical hypothyroidism represents an additional risk factor for coronary artery calcification, especially in subjects with intermediate and high cardiovascular risk scores
}

\author{
Nathalie Silva, Olga Santos, Felipe Morais ${ }^{3}$, Ilan Gottlieb ${ }^{\mathbf{1 , 2}}$, Macelo Hadlich², \\ Tamara Rothstein', Milena Tauil, Nathalia Veras, Mario Vaisman and \\ Patricia de Fátima Teixeira
}

Division of Endocrinology, ${ }^{1}$ Cardiovascular Imaging, Clínica de Diagnósticos por Imagem, ${ }^{2}$ Radiology Service, National Institute of Cardiology, and ${ }^{3}$ Radiology Department, Rua Rodolpho Paulo Rocco, 255, $9^{\circ}$ Andar, Serviço de Endocrinologia, Cidade Universitária, Ilha do Fundão, Rio de Janeiro RJ CEP 21941-913, Brazil
Correspondence should be addressed to N Silva

Email

nathalieaos@gmail.com

\begin{abstract}
Objective: Several studies have suggested an association between subclinical hypothyroidism (SCH) and increased cardiovascular risk. The aim of this study was to evaluate the presence of coronary artery disease (CAD) in asymptomatic patients with $\mathrm{SCH}$ by measuring the coronary artery calcium score (CACS).

Design: A total of 222 asymptomatic subjects (103 SCH and 119 euthyroid (EU)), who were between the ages of 35 and 65 years and had no previous history of CAD, were enrolled for this cross-sectional analysis.

Methods: The criteria for SCH included a confirmed normal serum free thyroxine and high TSH levels. Lipid profile, Framingham risk score (FRS) and CACS analyses were performed for all subjects.

Results: The SCH and EU groups were comparable with respect to age, gender, BMI and frequency of diabetes, systemic arterial hypertension, hypercholesterolaemia and smoking. There was no difference in the median CACS between the SCH and EU groups. However, in the subgroup of subjects with intermediate/high FRS ( AR $_{10 y} \geq 10 \%$ ), CACS was higher in the SCH subjects compared with EU subjects (EU vs SCH, $0.0(57.0)$ vs 23.0 (161.5); $P=0.045$ ). Multivariate analysis revealed that the risk for CACS $>100$ was independently associated with male gender, age $>55$ years, and the presence of simultaneous $S C H$ and $A R_{10 y} \geq 10 \%(O R=87.5(C l=2.1-3500) ; P=0.001)$. Serum TSH was positively correlated with CACS, especially in intermediate/high FRS subjects $\left(r_{\mathrm{s}}=0.301, P=0.045\right)$.
\end{abstract}

Conclusions: It was demonstrated that $\mathrm{SCH}$ represents an additional risk factor for CAD, notably in intermediate and high FRS subjects.

\section{Introduction}

Subclinical hypothyroidism (SCH), which affects $4-20 \%$ of the general population, is defined by an increased serum thyrotropin (TSH) concentration with a normal serum free thyroxine $\left(\mathrm{FT}_{4}\right)$ level $(1,2,3,4)$. SCH may be graded as mild (serum TSH, 4.5-9 mU/l) or moderate/severe (serum
$\mathrm{TSH}, \geq 10 \mathrm{mU} / \mathrm{l})$ (5), but its clinical significance remains controversial (6). One unanswered question is whether individuals with SCH have only biochemical abnormalities or whether there are significant effects of mild thyroid failure and perhaps the need for levothyroxine (L- $\mathrm{T}_{4}$ ) (c) 2014 European Society of Endocrinology Printed in Great Britain
Published by Bioscientifica Ltd. 
replacement $(7,8,9,10)$. Previous studies have also suggested an association between $\mathrm{SCH}$ and coronary artery disease (CAD) $(11,12,13,14)$. However, whether this association is related to $\mathrm{SCH}$-induced changes in the serum lipid profile or other classical cardiovascular (CV) risk factors remains unclear $(15,16)$. Some studies have found that subjects with $\mathrm{SCH}$ have higher serum total cholesterol (TC) and LDL cholesterol (LDL-C) levels compared with euthyroid (EU) subjects $(17,18)$. Despite these findings, the impact of $\mathrm{L}_{-} \mathrm{T}_{4}$ replacement on this endpoint, especially in the setting of mild thyroid dysfunction, has been somewhat conflicting in several studies $(19,20,21,22)$. To determine a causative effect between $\mathrm{SCH}$ and $\mathrm{CV}$ risk factors and possible $\mathrm{CV}$ events or mortality, several small clinical trials have assessed the impact of SCH treatment on different adverse endpoints such as dyslipidaemia and blood pressure. Although no clinical trials have assessed the impact of $\mathrm{L}_{-} \mathrm{T}_{4}$ replacement on CV events or mortality, indirect evidence from cohorts have suggested that part of the benefit of treating patients with SCH seems to be derived from a possible reduction in CV morbidity and mortality $(23,24,25)$.

Coronary calcification is extremely specific for atherosclerosis, and the amount of coronary calcium is a marker of the total atherosclerotic burden. As a result, the coronary artery calcium score (CACS) has been shown to be the best noninvasive method for $\mathrm{CV}$ event prediction in asymptomatic subjects $(26,27,28,29)$. The aim of this study was to evaluate the association between SCH and CACS and to correlate these findings with clinical and biochemical data.

\section{Subjects and methods}

\section{Study population}

This cross-sectional study was approved (protocol number 069/10) by the Ethical Committee of Clementino Fraga Filho University Hospital (HUCFF) in Rio de Janeiro, Brazil. Written informed consent was obtained from each patient.

A total of $103 \mathrm{SCH}$ outpatients and 119 individuals without thyroid dysfunction (EU subjects) were enrolled from September 2010 to April 2013. All participants were aged between 35 and 65 years at the time of enrolment.

$\mathrm{SCH}$ patients were recruited from the endocrine outpatient clinic of HUCFF. The controls were recruited among the patient escorts, hospital staff and volunteers without known CAD disease.
To be eligible for inclusion, $\mathrm{SCH}$ patients had to show slightly increased serum TSH levels $(4.0<\mathrm{TSH}<$ $10.0 \mathrm{mU} / \mathrm{l})$ and normal serum $\mathrm{FT}_{4}$ levels (0.8-1.9 $\left.\mathrm{ng} / \mathrm{dl}\right)$ in at least two measurements taken no $<2$ months apart. All SCH patients had autoimmune primary hypothyroidism. The control group had no history of thyroid disease and had normal values for serum $\mathrm{TSH}, \mathrm{FT}_{4}$ and anti-thyroid peroxidase antibody (TPO-Ab). The exclusion criteria for this study included known CAD, use of drugs that could interfere with thyroid function or the lipid profile (e.g. statins), use of anti-platelet drugs, hospitalisation within the last 2 months, pregnancy and a history of any disease known to interfere with circulating thyroid hormone levels (e.g. nephrotic syndrome, renal failure, liver failure and AIDS).

\section{Clinical and biochemical parameters}

Specific anamnesis and general physical examinations were done. The Framingham risk score (FRS) was calculated according to the data obtained, including gender, age, serum TC, serum HDL-C, systolic blood pressure and smoking status (30). According to the FRS, all diabetic patients were classified as high risk (>20\%). Height and weight were measured with participants barefoot and wearing light clothing. Systolic and diastolic blood pressures were measured in each arm with the patients at rest for at least $10 \mathrm{~min}$, with a 5 min interval between measurements, using a pneumatic sphygmomanometer. BMI was calculated as weight $(\mathrm{kg})$ divided by height squared $\left(\mathrm{m}^{2}\right)$.

The blood samples were collected from patients after $12 \mathrm{~h}$ of fasting. This analysis was performed at a maximum interval of 4 months before cardiac computed tomography (CT) imaging. Serum measurements of TSH, $\mathrm{FT}_{4}, \mathrm{TPO}-\mathrm{Ab}$, TC, triglycerides (TGs), HDL-C, LDL-C, non-HDL-C and glucose were carried out. The samples were centrifuged and analysed immediately after collection. The serum $\mathrm{TSH}, \mathrm{FT}_{4}$ and TPO-Ab levels were measured by immunochemiluminescence (Immulite 2000; DPC (Diagnostic Products Corporation, Los Angeles, CA, USA). The reference ranges for $\mathrm{TSH}$ and $\mathrm{FT}_{4}$ were $0.4-4.0 \mathrm{mU} / \mathrm{ml}$ and $0.8-1.9 \mathrm{ng} / \mathrm{dl}$, respectively, and a TPO-Ab level $>35 \mathrm{IU} / \mathrm{ml}$ was considered positive. Intra-assay coefficients of variation (CV) were 3.8-12.5, 4.4-7.5, and 4.3-5.6\%, and inter-assay CV were 4.6-12.5, 4.8-9.0 and $7.8-10.5 \%$ for $\mathrm{TSH}_{1} \mathrm{FT}_{4}$ and $\mathrm{TPO}-\mathrm{Ab}$ respectively.

The levels of TC, TG and HDL-C were measured with an immunoenzymatic assay kit (Dimension Flex, Siemens, Erlangen, Germany). LDL-C was calculated using the 
Friedewald equation, where $\mathrm{LDL}=(\mathrm{TC}-\mathrm{HDL})-(\mathrm{TG} / 5)$. Non-HDL-C was calculated using the following formula: non-HDL-C $=\mathrm{TC}-\mathrm{HDL}-\mathrm{C}$. Reference ranges for $\mathrm{TC}$, HDL-C, TG and LDL-C were based on the Adult Treatment Panel III of the National Cholesterol Education Program (NCEP) (30). Glucose was measured using the kinetic u.v. hexokinase method with a Dade Behring Dimension RXL analyser. The reference range for glucose was 70-99 mg/dl The sensitivity of the method was $0.80 \mathrm{mg} / \mathrm{dl}$, with interand intra-assay CV being 1.4 and $2.82 \%$ respectively.

\section{Cardiac CT imaging: CACS}

CACS scans were performed using 64-slice (Somatom Sensation, Siemens) and 256-slice (Brilliance iCT, Philips, Best, The Netherlands) scanners with the following standard parameters: axial acquisition with collimation, $32 \times 3 \mathrm{~mm}$ and no gap, and $65 \%$ (for Siemens) or $75 \%$ (for Philips) cardiac phases. The tube voltage was $120 \mathrm{kVp}$, and the amperage was adjusted according to body habitus. The Agatston calcium score was calculated for all exams in offline remote workstations (Leonardo for Siemens and Philips Portal) (31). We carefully followed the calcium scoring protocol recommended in current guidelines (32). The inter scanner variability for the calcium score between a 64 multi-slice scanner and Electron Beam CT was previously studied by Mao et al. (33), who demonstrated an inter scanner agreement of $99 \%$ for the presence of coronary calcium and a strong linear relationship between the two scanners (33).

According to their CACS values, the participants were classified as follows: $\mathrm{CACS}=0$, no calcification; $0.1 \geq \mathrm{CACS} \leq 100$, mild calcification and CACS $>100$, moderate to severe calcification (34).

\section{Statistical analysis}

Statistical analysis was performed using the SPSS for Windows programme, version 13.0. Continuous variables were reported as median values (interquartile range) and compared between two groups using the Mann-Whitney $U$ test because the majority of variables were not uniformly distributed. Comparisons among three or more groups were assessed with the Kruskal-Wallis test. Categorical variables were expressed as percentages and compared with the $\chi^{2}$ test or Fisher's exact test. Analysis of the correlation between two variables was performed using Spearman's correlation coefficient $\left(r_{\mathrm{s}}\right)$. A $P$ value $<0.05$ was considered to be statistically significant.
Binary logistic regression was applied to detect, in multivariate analysis, the specific covariates that were independently associated with a CACS $>100$. Those covariates were included in three steps (method=enter), with the following variables included in the first step: high blood pressure, diabetes, dyslipidaemia, obesity, male gender, age $>55$ years, smoking habits and isolated $\mathrm{SCH}$. In the second step, absolute risk of a CV event in 10 years $\left(\mathrm{AR}_{10 \mathrm{y}}\right) \geq 10 \%$ was added to the analysis, and the presence of simultaneous or combined SCH $+\mathrm{AR}_{10 \mathrm{y}} \geq 10 \%$ was added to the third step. Stratified analysis was also performed to detect differences in specific comparisons according to specific groups $\left(\mathrm{AR}_{10 \mathrm{y}} \geq 10\right.$ or $\left.<10 \%\right)$.

\section{Results}

The clinical and biochemical analysis results for all 222 enrolled subjects (103 SCH and $119 \mathrm{EU}$ ) are summarised in Table 1. The SCH and EU groups were similar in terms of gender distribution, age, BMI and frequencies of diabetes,

Table 1 Comparison of clinical and biochemical characteristics according to thyroid function. Continuous variables: median (interquartile range).

\begin{tabular}{|c|c|c|c|}
\hline & \multicolumn{3}{|c|}{ Total } \\
\hline & $\mathrm{SCH}(n=103)$ & $\mathrm{EU}(n=119)$ & $P$ value \\
\hline Age (years) & $54.0(12.3)$ & $52.3(12.0)$ & 0.990 \\
\hline Female (\%) & 82.6 & 78.1 & 0.214 \\
\hline TSH (mU/ml) & $5.8(2.6)$ & $1.7(1.2)$ & $<0.001$ \\
\hline $\mathrm{FT}_{4}(\mathrm{ng} / \mathrm{dl})$ & $1.0(0.2)$ & $1.2(0.3)$ & $<0.001$ \\
\hline Smoking (\%) & 6.9 & 9 & 0.145 \\
\hline Diabetes (\%) & 11.7 & 7.9 & 0.240 \\
\hline Hypertension (\%) & 41.4 & 33.7 & 0.288 \\
\hline Obesity (\%) & 40.4 & 30.3 & 0.361 \\
\hline BMI $\left(\mathrm{kg} / \mathrm{m}^{2}\right)$ & $28.4(7.8)$ & $27.3(6.9)$ & 0.580 \\
\hline $\mathrm{SBP}(\mathrm{mmHg})$ & $130.0(27.0)$ & $120.0(20.0)$ & 0.480 \\
\hline $\mathrm{DBP}(\mathrm{mmHg})$ & $80.0(20)$ & $80.0(20)$ & 0.740 \\
\hline FBG (mg/dl) & $93.0(14.0)$ & $93(13.0)$ & 0.570 \\
\hline $\mathrm{TC}(\mathrm{mg} / \mathrm{dl})$ & $201.5(48.5)$ & $211.0(57.0)$ & 0.308 \\
\hline HDL-C (mg/dl) & $47.0(15.2)$ & $58.0(21.0)$ & $<0.001$ \\
\hline LDL-C (mg/dl) & $125.5(22.0)$ & $128.0(48.0)$ & 0.896 \\
\hline TG $(\mathrm{mg} / \mathrm{dl})$ & $116.0(82.5)$ & $98.0(73.0)$ & 0.010 \\
\hline Non-HDL-C (mg/dl) & $153.0(54.0)$ & $154.0(56.0)$ & 0.392 \\
\hline FRS & $12.0(5.0)$ & $11.0(5.0)$ & 0.002 \\
\hline $\mathrm{AR}_{10 \mathrm{y}}(\%)$ & $4.9 \pm 6(2.2)$ & $3.8 \pm 5.4(2.2)$ & 0.048 \\
\hline Low $A_{10 y}(\%)$ & 84.3 & 85.2 & \\
\hline Intermediate $\mathrm{AR}_{10 \mathrm{y}}(\%)$ & 4.9 & 7.0 & 0.628 \\
\hline High $A R_{10 y}(\%)$ & 10.8 & 7.8 & \\
\hline
\end{tabular}

$\mathrm{SCH}$, subclinical hypothyroidism; $\mathrm{EU}$, euthyroid; $\mathrm{TSH}$, thyrotropin; $\mathrm{FT}_{4}$ free thyroxine; SBP, systolic blood pressure; DBP, diastolic blood pressure; FBG, fasting blood glucose; TC, total cholesterol; HDL-C, HDL cholesterol; LDL-C, LDL cholesterol; TG, triglyceride; FRS, Framingham risk score; $A R_{10 y}$ absolute risk of cardiovascular event in 10 years by FRS. 
systemic arterial hypertension, hypercholesterolaemia and smoking. Higher TG $(P=0.01)$ and lower HDL-C levels $(P=0.001)$ were found in the $\mathrm{SCH}$ group. The serum TSH level in the SCH group ranged from 4.1 to $10.0 \mathrm{mU} / \mathrm{l}$, and those in the control group ranged from 0.5 to $3.9 \mathrm{mU} / \mathrm{l}$. The serum $\mathrm{FT}_{4}$ level in the $\mathrm{SCH}$ and control group ranged from 0.8 to $1.8 \mathrm{ng} / \mathrm{dl}$.

The absolute risk of a CV event in 10 years $\left(\mathrm{AR}_{10 y}\right)$ was analysed by splitting the results into three FRS categories: low risk $(<10 \%)$, intermediate risk (10-20\%) and high risk (>20\%). The SCH and EU groups were comparable with respect to the frequencies of FRS categories, with most subjects showing a low risk (Table 1). However, the mean $\mathrm{AR}_{10 \mathrm{y}}(2.2$ (5.0) vs 2.2 (3.0); $P=0.048)$ and mean FRS $(P=0.002)$ values were higher in the $\mathrm{SCH}$ group in each category.

There were no differences in the mean CACS between the $\mathrm{SCH}$ and EU groups in a global analysis, and the frequency of CACS $>100$ was not higher in the SCH group.

After evaluating all participants, SCH was not associated with a high risk for moderate to severe calcification in the bivariate analysis $(\mathrm{OR}=1.448 \quad(\mathrm{CI}=0.575-0.364)$; $P=0.430$ ) or multivariate analysis (Table 2). Logistic binary regression detected that the risk for a CACS $>100$ was independently associated with male gender, age $>55$ years and the presence of simultaneous $\mathrm{SCH}$ and $\mathrm{AR}_{10 \mathrm{y}}$ $\geq 10 \%(\mathrm{OR}=87.5(\mathrm{CI}=2.1-3500) ; P=0.001)$, as given in Table 2 .

As the FRS findings differed significantly between the SCH and EU groups, we performed a stratified analysis of the CACS to compare more homogeneous groups. Specifically, the participants of both groups were divided according to their FRS $\mathrm{AR}_{10 y}$ into two categories: low risk $\left(\mathrm{AR}_{10 \mathrm{y}}<10 \%\right)$ and intermediate/high risk $\left(\mathrm{AR}_{10 \mathrm{y}} \geq 10 \%\right)$. These comparisons between SCH and EU subjects in the two categories of FRS $\mathrm{AR}_{10 y}$ (low risk and intermediate/ high risk) showed that all subjects were comparable in terms of age, gender, BMI, smoking, hypertension and diabetes frequency (Table 3).

When only the intermediate/high risk subgroup was considered, the mean CACS and the frequency of a CACS > 100 were higher among SCH subjects compared with EU subjects (Table 4).

Serum TSH was positively correlated with CACS in the intermediate/high risk subgroup $\left(r_{\mathrm{s}}=0.301\right.$, $P=0.045)$ but not in the entire group $\left(r_{\mathrm{s}}=0.088\right.$, $P=0.098)$. In addition, SCH was associated with a high risk for a CACS $>100$ in the intermediate/high risk group $(\mathrm{OR}=11.2(\mathrm{CI}=1.19-105) ; P=0.02)$, although this association was reduced when smoking was included in the multivariate analysis $(\mathrm{OR}=11.2(\mathrm{CI}=1.00-125)$; $P=0.050)$. However, smoking was not an independent risk factor for a CACS $>100$ in this subgroup of subjects, when other factors such as EFR category or SCH presence were considered $(\mathrm{OR}=11.2(\mathrm{CI}=0.99-128) ; P=0.852)$.

\section{Discussion}

To our knowledge, this is the second published study to evaluate the association between coronary disease and SCH using CACS evaluation. We observed that the CACS was higher and more severe in SCH patients when an intermediate/high risk for $\mathrm{CV}$ disease development was present $\left(\mathrm{AR}_{10 \mathrm{y}} \geq 10 \%\right)$. This result is in accordance with the hypothesis that $\mathrm{SCH}$ leads to atherosclerosis by

Table 2 Logistic binary regression analysis of the analysed parameters associated with the risk of CACS >100.

\begin{tabular}{|c|c|c|c|c|c|c|}
\hline \multirow[b]{2}{*}{ Variables } & \multicolumn{2}{|l|}{ Block $1^{a}$} & \multicolumn{2}{|l|}{ Block $2^{b}$} & \multicolumn{2}{|l|}{ Block $3^{c}$} \\
\hline & OR $(95 \% \mathrm{Cl})$ & $P$ value & OR $(95 \% \mathrm{Cl})$ & $P$ value & OR $(95 \% \mathrm{Cl})$ & $P$ value \\
\hline Hypertension & $0.87(0.20-3.9)$ & 0.85 & & & & \\
\hline Diabetes & $3.29(0.56-19.30)$ & 0.18 & & & & \\
\hline Dyslipidaemia & $2.41(0.40-14.74)$ & 0.34 & & & & \\
\hline Obesity (BMI $\geq 30$ ) & $0.99(0.22-4.59)$ & 0.99 & & & & \\
\hline Gender (male) & 7.47 (1.34-41.6) & 0.02 & $14.00(1.92-102.11)$ & 0.01 & $12.96(1.70-95.88)$ & 0.01 \\
\hline$>55$ years old & $3.41(0.63-18.5)$ & 0.15 & & & 7.47 (1.10-52.20) & 0.04 \\
\hline Smoking & $0.01(0.00-2.8)$ & 0.79 & & & & \\
\hline $\mathrm{SCH}$ & $1.9(0.35-10.45)$ & 0.46 & & & & \\
\hline Isolated $A R_{10 y} \geq 10 \%$ & & & $6.26(0.44-87.7)$ & 0.173 & & \\
\hline $\mathrm{SCH}+\mathrm{AR}_{10 \mathrm{y}} \geq 10 \%$ & & & & & $87.5(2.1-3500)$ & 0.02 \\
\hline
\end{tabular}


Table 3 Comparison of clinical and biochemical characteristics according to $\mathrm{AR}_{10 \mathrm{y}}$ by FRS. Continuous variables: median (interquartile range).

\begin{tabular}{|c|c|c|c|c|c|c|}
\hline & \multicolumn{3}{|c|}{ Low risk } & \multicolumn{3}{|c|}{ Intermediate/high risk } \\
\hline & $\mathrm{SCH}(87)$ & EU (102) & $P$ value & $\mathrm{SCH}(16)$ & EU (17) & $P$ value \\
\hline Age (years) & $53.0(13.1)$ & $51.2(11.5)$ & 0.230 & $57.0(8.7)$ & $56.7(9.3)$ & 0.191 \\
\hline female (\%) & 92.0 & 84.7 & 0.135 & 37.5 & 35.3 & 0.895 \\
\hline TSH (mU/l) & $6.2(2.4)$ & $1.7(1.2)$ & $<0.001$ & $5.1(2.1)$ & $1.6(1.4)$ & $<0.001$ \\
\hline $\mathrm{FT}_{4}(\mathrm{ng} / \mathrm{dl})$ & $1.0(0.2)$ & $1.1(0.3)$ & $<0.001$ & $1.0(0.3)$ & $1.2(0.3)$ & $<0.001$ \\
\hline Smoking (\%) & 5.3 & 10.0 & 0.270 & 16.7 & 0 & 0.060 \\
\hline Diabetes (\%) & 1.2 & 0 & 0.294 & 68.8 & 52.9 & 0.356 \\
\hline Hypertension (\%) & 37.3 & 29.2 & 0.294 & 66.7 & 56.3 & 0.576 \\
\hline Obesity (\%) & 40.0 & 33.0 & 0.300 & 42.9 & 37.5 & 0.400 \\
\hline BMI $\left(\mathrm{kg} / \mathrm{m}^{2}\right)$ & $28.0(8.4)$ & $28.8 \pm 6.0(28.0)$ & 0.943 & $28.7(6.6)$ & $26.0(6.8)$ & 0.682 \\
\hline SBP $(\mathrm{mmHg})$ & $124.0(23.5)$ & $120.0(30.0)$ & 0.976 & $144.5(30.0)$ & $120.0(56.7)$ & 0.352 \\
\hline DBP $(\mathrm{mmHg})$ & $80.0(10.0)$ & $80.0(10.0)$ & 0.965 & $90.0(27.0)$ & $75.0(45.0)$ & 0.476 \\
\hline FBG (mg/dl) & $92.0(14.0)$ & $91.0(11.0)$ & 0.552 & $110.0(44.0)$ & $109.0(16.8)$ & 0.520 \\
\hline TC (mg/dl) & $203.0(47.0)$ & $211.0(53.3)$ & 0.313 & $190.0(93)$ & $201.0(59.5)$ & 0.892 \\
\hline HDL-C (mg/dl) & $48.0(17.0)$ & $59.0(22.0)$ & $<0.001$ & $39(12)$ & $46(23.5)$ & 0.160 \\
\hline LDL-C (mg/dl) & $127.0(145)$ & $130.0(51.7)$ & 0.955 & $108.0(23.5)$ & $117.0(54.5)$ & 0.892 \\
\hline TG (mg/dl) & $113.0(64.0)$ & $97.0(59.7)$ & 0.021 & $175.0(152.0)$ & $122(12.0)$ & 0.322 \\
\hline Non-HDL-C (mg/dl) & $154.0(50.0)$ & 154.5 (57.5) & 0.557 & 153.0 (153) & $155.0(46.5)$ & 0.892 \\
\hline
\end{tabular}

$\mathrm{SCH}$, subclinical hypothyroidism; EU, euthyroid; $\mathrm{TSH}$, tyrotropin; $\mathrm{FT}_{4}$, free thyroxine; SBP, systolic blood pressure; DBP, diastolic blood pressure; FBG, fasting blood glucose; TC, total cholesterol; HDL-C, HDL cholesterol; LDL-C, LDL cholesterol; TG, triglyceride; FRS, Framingham risk score; $\mathrm{AR}_{10 y}$, absolute risk of cardiovascular event in 10 years by FRS

augmenting classical CV risk factors such as dyslipidaemia and systemic hypertension (6). Indeed, positive correlations between serum TSH and blood pressure $(35,36)$ and between TSH and serum lipids $(2,37,38)$ have been demonstrated in several studies. In addition, a potential relationship between $\mathrm{SCH}$ and metabolic syndrome and a reduction in insulin sensitivity have also been proposed $(39,40)$, and $\mathrm{SCH}$ also seems to be associated with additional CV risk factors.

The results of this study are consistent with the findings of a recent publication (41) showing a higher CACS in male $\mathrm{SCH}$ patients. However, this previous study only evaluated subjects with an intermediate/high CV risk, most of them males, which most likely explains the weak association between SCH and an abnormal CACS in females. This previous study also evaluated coronary $\mathrm{CT}$ angiography and found no difference in the prevalence of obstructive CAD between the SCH and EU groups.
The population evaluated in this study was mostly female, which is consistent with the higher prevalence of SCH among the female population in general (4). In addition, we performed a subgroup analysis of low and intermediate/high FRS subjects, whereas the previous study only evaluated intermediate to high-risk subjects in a retrospective approach.

The positive correlation between serum TSH levels and CACS also supports recent findings showing that a higher CAD risk has been linked to serum TSH levels $>7.0 \mathrm{mU} / 1$ (11). Predicting CAD risk in asymptomatic individuals is challenging in clinical practice, and the CACS is a useful screening tool $(27,42,43)$. Coronary calcification is highly specific for atherosclerosis and represents the cumulative effects of risk factors and vascular age (44). In particular, greater numbers of atherosclerotic plaques are associated with increased plaque instability, with an increasing risk of acute coronary events (26). The Multi-Ethnic Study

Table 4 CACS results according to thyroid function and FRS. Continuous variables: median (interquartile range).

\begin{tabular}{|c|c|c|c|c|c|c|c|c|c|}
\hline & \multicolumn{3}{|c|}{ Total } & \multicolumn{3}{|c|}{ Low risk } & \multicolumn{3}{|c|}{ Intermediate/high risk } \\
\hline & $\mathrm{SCH}$ & EU & $P$ value & $\mathrm{SCH}$ & EU & $P$ value & $\mathrm{SCH}$ & EU & $P$ value \\
\hline CACS & $0.0(11.3)$ & $0.0(4.0)$ & 0.389 & $0.0(0.0)$ & $0.0(3.2)$ & 0.036 & $23.0(161.5)$ & $0.0(57.0)$ & 0.045 \\
\hline CACS > $100(n / \%)$ & 10/9.7 & 9/7.6 & 0.582 & $3 / 3.5$ & $8 / 8.2$ & 0.182 & $7 / 43.8$ & $1 / 5.9$ & 0.01 \\
\hline
\end{tabular}

CACS, coronary artery calcium score; FRS, Framingham risk score; SCH, subclinical hypothyroidism; EU, euthyroid; $n$, total numbers. 
of Atherosclerosis (MESA) demonstrated the usefulness of the CACS as a CAD screening test, notably in the female subgroup where the FRS presents low accuracy $(45,46)$. The absence of coronary calcification in asymptomatic patients is associated with a good CV prognosis, whereas in symptomatic patients or individuals with risk factors, a negative CACS evaluation should be followed by another diagnostic test, as there is a high risk for non-calcified coronary plaques in such patients (47). CACS may also be used to identify and stratify high-risk patients, such as uremic patients, to implement preventive strategies, as demonstrated by Splendiani et al. (48).

The major limitation of this study was the choice of a cross-sectional design, as this approach does not support an analysis of cause or consequence. Another limitation was the lack of information concerning the duration of thyroid disease in all studied individuals and the presence of other $\mathrm{CV}$ risk factors that are not assessed in the FRS. For example, alcohol consumption was one such factor not evaluated in this study.

In conclusion, we found that $\mathrm{SCH}$ may represent an additional risk factor for CAD, notably among intermediate and high FRS patient subgroups. In this context, it is imperative that randomised, placebo-controlled studies be carried out to explore the impact of $\mathrm{L}_{-} \mathrm{T}_{4}$ in minimising $\mathrm{CV}$ risk in this population.

\section{Declaration of interest}

The authors declare that there is no conflict of interest that could be perceived as prejudicing the impartiality of the research reported.

\section{Funding}

This research did not receive any specific grant from any funding agency in the public, commercial or not-for-profit sector.

\section{References}

1 Cooper DS. Clinical practice. Subclinical hypothyroidism. New England Journal of Medicine 2001345 260-265. (doi:10.1056/ NEJM200107263450406)

2 Canaris GJ, Manowitz NR, Mayor G \& Ridgway EC. The Colorado thyroid disease prevalence study. Archives of Internal Medicine $2000 \mathbf{1 6 0}$ 526-534. (doi:10.1001/archinte.160.4.526)

3 Vanderpump MP, Tunbridge WM, French JM, Appleton D, Bates D, Clark F, Grimley Evans J, Hasan DM, Rodgers H, Tunbridge F et al. The incidence of thyroid disorders in the community: a twenty-year follow-up of the Whickham Survey. Clinical Endocrinology 199543 55-68. (doi:10.1111/j.1365-2265.1995.tb01894.x)

4 Hollowell JG, Staehling NW, Flanders WD, Hannon WH, Gunter EW, Spencer CA \& Braverman LE. Serum TSH, T(4), and thyroid antibodies in the United States population (1988 to 1994): National Health and Nutrition Examination Survey (NHANES III). Journal of Clinical Endocrinology and Metabolism 200287 489-499. (doi:10.1210/jcem. 87.2.8182)

5 Cooper DS \& Biondi B. Subclinical thyroid disease. Lancet 2012379 1142-1154. (doi:10.1016/S0140-6736(11)60276-6)

6 Biondi B \& Cooper DS. The clinical significance of subclinical thyroid dysfunction. Endocrine Reviews 200829 76-131. (doi:10.1210/er. 2006-0043)

7 McDermott MT \& Ridgway EC. Subclinical hypothyroidism is mild thyroid failure and should be treated. Journal of Clinical Endocrinology and Metabolism 200186 4585-4590. (doi:10.1210/jcem.86.10.7959)

8 Almandoz JP \& Gharib H. Hypothyroidism: etiology, diagnosis, and management. Medical Clinics of North America 201296 203-221. (doi:10.1016/j.mcna.2012.01.005)

9 Garber JR, Cobin RH, Gharib H, Hennessey JV, Klein I, Mechanick JI, Pessah-Pollack R, Singer PA, Woeber KA, American Association of Clinical E et al. Clinical practice guidelines for hypothyroidism in adults: cosponsored by the American Association of Clinical Endocrinologists and the American Thyroid Association. Endocrine Practice 2012 18 988-1028. (doi:10.4158/EP12280.GL)

10 Sgarbi JA, Teixeira PF, Maciel LM, Mazeto GM, Vaisman M, Montenegro Junior RM \& Ward LS. The Brazilian consensus for the clinical approach and treatment of subclinical hypothyroidism in adults: recommendations of the Thyroid Department of the Brazilian Society of Endocrinology and Metabolism. Arquivos Brasileiros de Endocrinologia e Metabologia 201357 166-183. (doi:10.1590/S000427302013000300003)

11 Rodondi N, den Elzen WP, Bauer DC, Cappola AR, Razvi S, Walsh JP, Asvold BO, Iervasi G, Imaizumi M, Collet TH et al. Subclinical hypothyroidism and the risk of coronary heart disease and mortality. Journal of the American Medical Association 2010304 1365-1374. (doi:10.1001/jama.2010.1361)

12 Gencer B, Collet TH, Virgini V, Auer R \& Rodondi N. Subclinical thyroid dysfunction and cardiovascular outcomes among prospective cohort studies. Endocrine, Metabolic \& Immune Disorders Drug Targets 2013 13 4-12.

13 McQuade C, Skugor M, Brennan DM, Hoar B, Stevenson C \& Hoogwerf BJ. Hypothyroidism and moderate subclinical hypothyroidism are associated with increased all-cause mortality independent of coronary heart disease risk factors: a PreCIS database study. Thyroid 201121 837-843. (doi:10.1089/thy.2010.0298)

14 Tseng FY, Lin WY, Lin CC, Lee LT, Li TC, Sung PK \& Huang KC. Subclinical hypothyroidism is associated with increased risk for all-cause and cardiovascular mortality in adults. Journal of the American College of Cardiology 201260 730-737. (doi:10.1016/j.jacc. 2012.03.047)

15 Bakker SJ, ter Maaten JC, Popp-Snijders C, Slaets JP, Heine RJ \& Gans RO. The relationship between thyrotropin and low density lipoprotein cholesterol is modified by insulin sensitivity in healthy euthyroid subjects. Journal of Clinical Endocrinology and Metabolism 2001 86 1206-1211. (doi:10.1210/jcem.86.3.7324)

16 Muller B, Zulewski H, Huber P, Ratcliffe JG \& Staub JJ. Impaired action of thyroid hormone associated with smoking in women with hypothyroidism. New England Journal of Medicine 1995333 964-969. (doi:10.1056/NEJM199510123331503)

17 Duntas LH \& Brenta G. The effect of thyroid disorders on lipid levels and metabolism. Medical Clinics of North America 201296 269-281. (doi:10.1016/j.mcna.2012.01.012)

18 Pearce EN. Update in lipid alterations in subclinical hypothyroidism. Journal of Clinical Endocrinology and Metabolism 201297 326-333. (doi:10.1210/jc.2011-2532)

19 Villar HC, Saconato H, Valente O \& Atallah AN. hyroid hormone replacement for subclinical hypothyroidism. Cochrane Database of Systematic Reviews, 2007 CD003419. (doi:10.1002/14651858. CD003419.pub2) 
20 Adrees M, Gibney J, El-Saeity N \& Boran G. Effects of 18 months of L-T replacement in women with subclinical hypothyroidism. Clinical Endocrinology 200971 298-303. (doi:10.1111/j.1365-2265.2008. 03509.x)

21 Razvi S, Ingoe L, Keeka G, Oates C, McMillan C \& Weaver JU. The beneficial effect of L-thyroxine on cardiovascular risk factors, endothelial function, and quality of life in subclinical hypothyroidism: randomized, crossover trial. Journal of Clinical Endocrinology and Metabolism 200792 1715-1723. (doi:10.1210/jc.2006-1869)

22 Teixeira PF, Reuters VS, Ferreira MM, Almeida CP, Reis FA, Melo BA, Buescu A, Costa AJ \& Vaisman M. Treatment of subclinical hypothyroidism reduces atherogenic lipid levels in a placebo-controlled doubleblind clinical trial. Hormone and Metabolic Research 200840 50-55. (doi:10.1055/s-2007-993216)

23 Rodondi N, Bauer DC, Cappola AR, Cornuz J, Robbins J, Fried LP, Ladenson PW, Vittinghoff E, Gottdiener JS \& Newman AB. Subclinical thyroid dysfunction, cardiac function, and the risk of heart failure. The Cardiovascular Health Study. Journal of the American College of Cardiology 200852 1152-1159. (doi:10.1016/j.jacc.2008.07.009)

24 Razvi S, Weaver JU, Vanderpump MP \& Pearce SH. The incidence of ischemic heart disease and mortality in people with subclinical hypothyroidism: reanalysis of the Whickham Survey cohort. Journal of Clinical Endocrinology and Metabolism 201095 1734-1740. (doi:10.1210/ jc.2009-1749)

25 Razvi S, Weaver JU, Butler TJ \& Pearce SH. Levothyroxine treatment of subclinical hypothyroidism, fatal and nonfatal cardiovascular events, and mortality. Archives of Internal Medicine 2012172 811-817. (doi:10.1001/archinternmed.2012.1159)

26 Pletcher MJ, Tice JA, Pignone M \& Browner WS. Using the coronary artery calcium score to predict coronary heart disease events: a systematic review and meta-analysis. Archives of Internal Medicine 2004 164 1285-1292. (doi:10.1001/archinte.164.12.1285)

27 Detrano R, Guerci AD, Carr JJ, Bild DE, Burke G, Folsom AR, Liu K, Shea S, Szklo M, Bluemke DA et al. Coronary calcium as a predictor of coronary events in four racial or ethnic groups. New England Journal of Medicine 2008358 1336-1345. (doi:10.1056/ NEJMoa072100)

28 Bachar GN, Atar E, Fuchs S, Dror D \& Kornowski R. Prevalence and clinical predictors of atherosclerotic coronary artery disease in asymptomatic patients undergoing coronary multidetector computed tomography. Coronary Artery Disease 200718 353-360. (doi:10.1097/ MCA.0b013e3281286529)

29 Taylor AJ, Cerqueira M, Hodgson JM, Mark D, Min J, O'Gara P, Rubin GD, American College of Cardiology Foundation Appropriate Use Criteria Task F, Society of Cardiovascular Computed T, American College of R et al. ACCF/SCCT/ACR/AHA/ASE/ASNC/NASCI/ SCAI/SCMR 2010 appropriate use criteria for cardiac computed tomography. A report of the American College of Cardiology Foundation Appropriate Use Criteria Task Force, the Society of Cardiovascular Computed Tomography, the American College of Radiology, the American Heart Association, the American Society of Echocardiography, the American Society of Nuclear Cardiology, the North American Society for Cardiovascular Imaging, the Society for Cardiovascular Angiography and Interventions, and the Society for Cardiovascular Magnetic Resonance. Circulation 2010122 e525-e555. (doi:10.1161/CIR.0b013e3181fcae66)

30 National Cholesterol Education Program (NCEP) Expert Panel on Detection, Evaluation, and Treatment of High Blood Cholesterol in Adults (Adult Treatment Panel III). Third Report of the National Cholesterol Education Program (NCEP) Expert Panel on Detection, Evaluation, and Treatment of High Blood Cholesterol in Adults (Adult Treatment Panel III) final report. Circulation 2002106 3143-3421.

31 Agatston AS, Janowitz WR, Hildner FJ, Zusmer NR, Viamonte M Jr \& Detrano R. Quantification of coronary artery calcium using ultrafast computed tomography. Journal of the American College of Cardiology 199015 827-832. (doi:10.1016/0735-1097(90)90282-T)

32 Greenland P, Bonow RO, Brundage BH, Budoff MJ, Eisenberg MJ, Grundy SM, Lauer MS, Post WS, Raggi P, Redberg RF et al. ACCF/AHA clinical expert consensus document on coronary artery calcium scoring by computed tomography in global cardiovascular risk assessment and in evaluation of patients with chest pain: a report of the American College of Cardiology Foundation Clinical Expert Consensus Task Force (ACCF/AHA Writing Committee to Update the 2000 Expert Consensus Document on Electron Beam Computed Tomography) developed in collaboration with the Society of Atherosclerosis Imaging and Prevention and the Society of Cardiovascular Computed Tomography. Journal of the American College of Cardiology 200749 378-402. (doi:10.1016/j.jacc.2006.10.001)

33 Mao SS, Pal RS, McKay CR, Gao YG, Gopal A, Ahmadi N, Child J, Carson S, Takasu J, Sarlak B et al. Comparison of coronary artery calcium scores between electron beam computed tomography and 64-multidetector computed tomographic scanner. Journal of Computer Assisted Tomography 200933 175-178. (doi:10.1097/RCT. Ob013e31817579ee)

34 Rumberger JA, Brundage BH, Rader DJ \& Kondos G. Electron beam computed tomographic coronary calcium scanning: a review and guidelines for use in asymptomatic persons. Mayo Clinic Proceedings 199974 243-252. (doi:10.4065/74.3.243)

35 Liu D, Jiang F, Shan Z, Wang B, Wang J, Lai Y, Chen Y, Li M, Liu H, Li C et al. A cross-sectional survey of relationship between serum TSH level and blood pressure. Journal of Human Hypertension 201024 134-138. (doi:10.1038/jhh.2009.44)

36 Ferreira MM, Teixeira Pde F, Mansur VA, Reuters VS, Almeida CP \& Vaisman M. Ambulatory blood pressure monitoring in normotensive patients with subclinical hypothyroidism. Arquivos Brasileiros de Cardiologia 201094 806-812. (doi:10.1590/S0066782X2010005000040)

37 Vierhapper H, Nardi A, Grosser P, Raber W \& Gessl A. Low-density lipoprotein cholesterol in subclinical hypothyroidism. Thyroid 200010 981-984. (doi:10.1089/thy.2000.10.981)

38 Wang CY, Chang TC \& Chen MF. Associations between subclinical thyroid disease and metabolic syndrome. Endocrine Journal 201259 911-917. (doi:10.1507/endocrj.EJ12-0076)

39 Brenta G, Berg G, Arias P, Zago V, Schnitman M, Muzzio ML, Sinay I \& Schreier L. Lipoprotein alterations, hepatic lipase activity, and insulin sensitivity in subclinical hypothyroidism: response to L-T(4) treatment. Thyroid 200717 453-460. (doi:10.1089/thy.2006.0302)

40 Teixeira PF, Cabral MD, Silva NA, Soares DV, Braulio VB, Couto AP, Henriques JL, Costa AJ, Buescu A \& Vaisman M. Serum leptin in overt and subclinical hypothyroidism: effect of levothyroxine treatment and relationship to menopausal status and body composition. Thyroid 2009 19 443-450. (doi:10.1089/thy.2007.0393)

41 Park YJ, Lee YJ, Choi SI, Chun EJ, Jang HC \& Chang HJ. Impact of subclinical hypothyroidism on the coronary artery disease in apparently healthy subjects. European Journal of Endocrinology 2011165 115-121. (doi:10.1530/EJE-11-0014)

42 Budoff MJ, Shaw LJ, Liu ST, Weinstein SR, Mosler TP, Tseng PH, Flores FR, Callister TQ, Raggi P \& Berman DS. Long-term prognosis associated with coronary calcification: observations from a registry of 25,253 patients. Journal of the American College of Cardiology 200749 1860-1870. (doi:10.1016/j.jacc.2006.10.079)

43 Shaw LJ, Raggi P, Schisterman E, Berman DS \& Callister TQ. Prognostic value of cardiac risk factors and coronary artery calcium screening for all-cause mortality. Radiology 2003228 826-833. (doi:10.1148/radiol. 2283021006)

44 Shaw LJ, Raggi P, Berman DS \& Callister TQ. Coronary artery calcium as a measure of biologic age. Atherosclerosis 2006188 112-119. (doi:10.1016/j.atherosclerosis.2005.10.010)

45 Bild DE, Bluemke DA, Burke GL, Detrano R, Diez Roux AV, Folsom AR, Greenland P, Jacob DR Jr, Kronmal R, Liu K et al. Multi-Ethnic Study of 
Atherosclerosis: objectives and design. American Journal of Epidemiology 2002156 871-881. (doi:10.1093/aje/kwf113)

46 McClelland RL, Chung H, Detrano R, Post W \& Kronmal RA. Distribution of coronary artery calcium by race, gender, and age: results from the Multi-Ethnic Study of Atherosclerosis (MESA). Circulation 2006113 30-37. (doi:10.1161/CIRCULATIONAHA. 105.580696)
47 Gottlieb I, Sara L, Brinker JA, Lima JA \& Rochitte CE. CT coronary calcification: what does a score of ' 0 ' mean? Current Cardiology Reports 201113 49-56. (doi:10.1007/s11886-010-0151-4)

48 Manni M, Coen G, Balducci A, Morosetti M, Jankovic L, Mantella D, Vega A, Naticchia A, Sorbo G, Taccone Gallucci M et al. Cardiac calcifications in hemodialysis patients assessed with spiral computed tomography. Minerva Urologica e Nefrologica 200658 181-188.

Received 19 January 2014

Revised version received 18 May 2014

Accepted 10 June 2014 